\title{
AGRONEGÓCIO DA AGRICULTURA FAMILIAR COM A CULTURA DE MANGA NO DISTRITO MANIÇOBA EM JUAZEIRO (BA) ${ }^{1}$
}

\section{Marcelo Dantas Matos da Paz* Denes Dantas Vieira**}

RESUMO: O desenvolvimento das áreas irrigadas tem possibilitado que regiões interioranas, a exemplo do sertão nordestino, destaquem-se na produção, comercialização e geração de renda relacionada ao trabalho com cultivo de frutas tropicais. O presente artigo tem como objetivo analisar a experiência de construção e desenvolvimento do agronegócio, a partir do trabalho de agricultores familiares na produção e comercialização da manga no Vale do São Francisco. Para a realização da pesquisa foi feito um estudo de caso com agricultores da Associação de Produtores Rurais de Campos, no perímetro irrigado do distrito de Maniçoba no município de Juazeiro (BA). Foram utilizados os conceitos teóricos e metodológicos de babitus, campo e capital do sociólogo francês Pierre Bourdieu. Através do estudo das trajetórias sociais e do campo de relações de dois produtores, os resultados apontam para construção de estratégias de produção, comercialização e gestão diferenciadas na forma como esses produtores realizam o agronegócio, isto é revelado através das complexas e desiguais maneiras como esses produtores rurais acumularam, ao longo de suas trajetórias, capital econômico, social e cultural.

PALAVRAS-CHAVE: Agronegócio; Capital; Manga; Trajetória social.

\section{AGRIBUSINESS IN FAMILIAL AGRICULTURE OF MANGOES IN THE MANIÇOBA DISTRICT, JUAZEIRO, BRAZIL}

ABSTRACT: Irrigation has triggered the development of the Brazilian northeastern hinterland and enhanced production, commercialization and income due to the cultivation of tropical fruits. The establishment and development of agribusiness is analyzed through the experience of familial agriculture in the production and commercialization of mangoes in the Vale do São Francisco, Brazil. A study case on rural workers from the Association of Rural Producers of Campos within the irrigated

1 Artigo produzido a partir das atividades acadêmicas do Núcleo Temático: Observatório do Agronegócio da Universidade Federal do Vale do São Francisco (UNIVASF).

* Graduando em Engenharia Civil pela Universidade Federal do Vale do São Francisco (UNIVASF), Brasil.

** Docente da Universidade Federal do Vale do São Francisco; Coordenador do Programa de Pós-Graduação em Extensão Rural (PPGExR - UNIVASF), Juazeiro (BA), Brasil; E-mail: denes.vieira@univasf.edu.br 
area of the Maniçoba district, Juazeiro BA Brazil, is investigated. Pierre Bourdieu's theoretical and methodological concepts of habitus, field and capital have been employed. Results of field studies and the social trajectories of two rural producers have indicated the construction of different production, commercialization and management strategies employed in their agribusinesses. The above is shown through the complex and unequal manner by which rural producers accumulate economic, social and cultural capital.

KEY WORDS: Agribusiness; Capital; Mango; social Trajectory.

\section{INTRODUÇÃo}

O presente artigo tem seu foco no debate das interfaces entre as experiências de pequena e grande produção agropecuária. O agronegócio visto tradicionalmente como modelo de exportação dos produtos agrícolas se profissionalizou e conquistou mercados e consumidores em todo o mundo. A experiência brasileira do agronegócio, e em particular em relação ao que acontece no cenário do Vale do São Francisco, tem chamado atenção por sua pujança econômica em gerar renda, empregos e imagens de prosperidade e desenvolvimento, que são usadas para justificar suas iniciativas, apoios governamentais e uso intensivo dos recursos naturais disponíveis.

As regiões onde o agronegócio predomina têm atraído atenção de pesquisadores para estudar os efeitos das possíveis mudanças sociais e econômicas produzidas pelas inciativas produtivas. Emblemático das transformações produzidas pelos empreendimentos econômicos da agropecuária, que utiliza alta tecnologia e uso intensivo de agrotóxicos para atingir almejados índices de produtividade, o chamado agronegócio tem atraído contingentes cada vez maiores de populações migrantes, que buscam nessas regiões ondem predominam a prática intensiva da agropecuária, mais oportunidades de emprego e moradia (HEREDIA; PALMEIRA; LEITE, 2010).

A compreensão do agronegócio, ou agrobusiness, precisa ser ampliada para além da concepção dos negócios de uma agropecuária caracterizada por uma monocultura voltada, majoritariamente, para exportação. A pesquisa que resultou nesse artigo parte da compreensão de que é necessário contribuir com 
a ampliação dos estudos sobre essa temática. Apesar do entendimento de que a dimensão econômica e produtiva tem enorme relevância, este trabalho voltou-se para as análises das relações sociais de construção e organização de experiências de agronegócio no interior das unidades produtivas identificadas e reconhecidas como pequena produção.

A partir da pequena e média produção, também identificada como agricultura familiar, é proposto problematizar a construção de duas experiências de agronegócio com a produção da cultura da manga no Vale do São Francisco. A ideia dessa análise é buscar compreender como agricultores construíram suas experiências de produção com a manga, seus desafios e facilidades. Nesse sentido, foi realizada uma pesquisa com duas experiências de produtores do distrito do perímetro irrigado de Maniçoba no município baiano de Juazeiro.

O objetivo geral da pesquisa foi analisar a experiência de construção e desenvolvimento do agronegócio, a partir de elementos presentes na trajetória social de agricultores familiares no cultivo e comercialização da manga a partir de dois casos no Vale do São Francisco. Também se buscou compreender como esses produtores realizam a produção e comercialização de sua agricultura; estudar como os produtores têm acesso às políticas públicas de fomento ao empreendedorismo e assistência técnica; e identificar como os produtores se organizam para terem acesso aos mercados e nas disputas por representatividade política do agronegócio em seu território.

A pesquisa tem caráter qualitativo, o trabalho de campo foi realizado através de entrevistas semiestruturadas com oito pessoas que trabalham de diversas formas com a pequena produção de manga - dois são produtores: o primeiro é reconhecidamente identificado como o possuidor do maior número de lotes entre os integrantes da Associação de Campos; e o segundo possui apenas um lote e já foi presidente da Associação dos Produtores. A análise das duas experiências do agronegócio familiar é identificada no artigo, respectivamente, como caso 1 e caso 2.

Os demais agricultores entrevistados foram caracterizados como trabalhadores diaristas, ou empregados permanentes (são agricultores que vendem sua mão de obra para o agronegócio praticado na região). Ademais, também foram entrevistados dois analistas, funcionários da Companhia de Desenvolvimento dos 
Vales do São Francisco e do Parnaíba (CODEVASF) com experiência de trabalho nos perímetros irrigados de Juazeiro (BA) e Petrolina (PE). Metodologicamente foi realizada observação de campo, através da confecção de diários de pesquisa e análise de dados secundários obtidos através de instituições que lidam diretamente com a assessoria, assistência técnica e fomento ao desenvolvimento de empreendimentos nos perímetros irrigados do médio São Francisco.

\section{MATERIAIS E MÉTODOS}

Uma das questões iniciais dessa pesquisa foi a definição sobre qual seria o lócus do levantamento de informações e dados para a coleta da pesquisa empírica. Nesse sentido, foi decidido por um dos perímetros irrigados, Maniçoba, implementado pela CODEVASF.

Para a análise das informações coletadas foi feita a opção pelos conceitos teóricos e metodológicos de habitus, campo e capital, a partir do pensamento do sociólogo Pierre Bourdieu. Para Bourdieu (2011a), o agente (o autor trabalha com a categoria agente, e não indivíduo ou sujeito) acumula diferentes formas de capital - econômico (bens materiais, dinheiro), social (redes de relacionamentos, reciprocidade etc), cultural (títulos, escolaridade, conhecimento), a longo de suas trajetórias sociais. E, a partir da aquisição de alguma dessas formas de capital, o agente exibe em seu campo de relações (família, trabalho, na comunidade, na sua rua, nos espaços onde tem atuação etc.), outra forma de capital, que Bourdieu (2011a) chama de capital simbólico - prestígio, honra, reconhecimento.

Através desta perspectiva teórica, desdobraremos nossas análises com a compreensão de que os agentes sociais, aqui compreendidos como os agricultores, constroem o seu babitus (disposição para agir, esquemas mentais adquiridos ao longo de suas trajetórias sociais) e acumulam formas de capital variadas para serem usados nas suas disputas por um lugar social - posição entre os agricultores da manga na Associação dos Produtores Rurais de Campos, distrito irrigado de Maniçoba em Juazeiro (BA). O artigo não tem pretensão de realizar uma vasta revisão teórica dos conceitos aqui apresentados. É priorizada a análise dos dados empíricos na pesquisa 
realizada com o intuito de oferecer uma contribuição à ampliação dos olhares sobre o agronegócio e suas múltiplas formas de apropriação pelos agricultores.

Essas formas de capital os agentes usam em seus campos de relações, no trabalho, por exemplo. $\mathrm{O}$ artigo mostra os agentes sociais, agricultores no cultivo da manga, em um processo de acumulação e uso de diferentes formas de capital na conquista e resistência de posições sociais no campo de relações construído entre os pequenos produtores de manga do Vale do São Francisco.

\subsection{ESPAÇO SOCIAL DO PERÍMETRO IRRIGADO DO DISTRITO DE MANIÇOBA}

Localizado a 36 quilômetros da cidade de Juazeiro (BA), o Perímetro Irrigado de Maniçoba é um importante polo produtor de alimentos do Vale do São Francisco, destacando-se a produção de frutas. Dentre elas, a manga representando cerca de $75 \%$ da produção, seguida do coco com $11 \%$ e da uva com $4 \%$. Outras culturas como a goiaba, mamão, maracujá e melancia representam uma parcela menor desta produção.

O Distrito Irrigado do Perímetro de Maniçoba (DIM), cujo início remonta aos anos 80, conta hoje com uma ampla infraestrutura, formada por 5,6 quilômetros de adutoras, 2 quilômetros de aquedutos e mais de 126 quilômetros de canais de irrigação, segundo dados da CODEVASF.

Tabela 1. Área irrigável no Perímetro Irrigado de Maniçoba

\begin{tabular}{lrrrr}
\hline Área irrigada & Origem & \multicolumn{1}{c}{ Atual } & \multicolumn{1}{c}{$\begin{array}{c}\text { Lotes } \\
\text { Originais }\end{array}$} & $\begin{array}{c}\text { Lotes } \\
\text { Atuais }\end{array}$ \\
\hline Área empresa & 2.567 & $3.872,98$ & 55 & 48 \\
Área colonização & 1.800 & $2.662,75$ & 234 & 243 \\
Associações & - & 737,63 & - & 131 \\
Terceiros & - & 664,03 & - & 50 \\
T o t a 1 & 4.367 & $8.269,00$ & 289 & 471 \\
\hline
\end{tabular}

Fonte: Distrito de Irrigação do Perímetro de Maniçoba.

De acordo com a CODEVASF, o DIM possui duas cooperativas e quatro 
associações de produtores, tornando representativa a área de cultivo em lotes de agricultores familiares, cerca de $64 \%$. Além disso, empresas agrícolas de médio e grande porte, como Agrovale, Ebras, Brasil Uvas, Hortibon, Frutibon e Agrobraz, também estão presentes na região. Estimativas mostram que foram gerados cerca de 4000 empregos diretos e 6000 empregos indiretos, com uma produção de quase 100 toneladas de alimentos no ano de 2014 , tendo a manga como o principal produto.

Tabela 2. Produção agrícola no perímetro irrigado de maniçoba

\begin{tabular}{cccccc}
\hline \multicolumn{5}{c}{ Valor Bruto da Produção $($ VBP) $-\mathbf{R} \$ \mathbf{1 . 0 0 0 , 0 0}$} \\
\hline \multirow{2}{*}{ Ano } & \multicolumn{2}{c}{ Área Familiar } & \multicolumn{2}{c}{ Área Empresarial } & \multirow{2}{*}{ Total } \\
\cline { 2 - 5 } & $\begin{array}{c}\text { Culturas } \\
\text { Temporárias }\end{array}$ & $\begin{array}{c}\text { Culturas } \\
\text { Permanentes }\end{array}$ & $\begin{array}{c}\text { Culturas } \\
\text { Temporárias }\end{array}$ & $\begin{array}{c}\text { Culturas } \\
\text { Permanentes }\end{array}$ & \\
\hline $2011^{*}$ & 730 & 33.149 & 8.194 & 40.652 & 82.682 \\
$2012^{*}$ & 472 & 44.982 & 927 & 46.941 & 93.322 \\
$2013^{*}$ & 531 & 60.036 & - & 60.320 & 120.886 \\
2014 & 116 & 48.262 & 1.736 & 38.663 & 88.776 \\
\hline
\end{tabular}

*Valores atualizados pelo Índice Nacional de Preços ao Consumidor (INPC) - Dezembro 2014. Fonte: CODEVASF (2016).

Os principais sistemas de irrigação são a irrigação por superfície, aspersão, micro aspersão e, em menor escala, gotejamento.

\section{RESULTADOS E DISCUSSÃO}

\subsection{OS DESAFIOS DO "NEGÓCIO" COM A PRODUÇÃO IRRIGADA - A EXPERIÊN- CIA DA ASSOCIAÇÃO}

A comunidade de Campos, de onde se origina o nome da organização dos seus agricultores - Associação dos Produtores Rurais de Campos - tem sua trajetória ligada ao projeto de irrigação do médio São Francisco e idealizado após a construção da barragem de Sobradinho, através da confecção dos projetos, que visaram otimizar 
o uso da água do reservatório para além da produção de energia. A produção e comercialização da fruticultura irrigada foram vistas como uma estratégia para atrair investimentos para a região e gerar renda e empregos para seus moradores.

Segundo um dos entrevistados dessa pesquisa, ex-presidente da Associação dos Produtores e um dos seus fundadores, a CODEVASF criou o projeto na região indenizando os colonos que ali viviam alegando que a região era de "terras públicas", ou seja, de propriedade da União. Feito isso, a companhia ofereceu os lotes para todos os moradores, porém muitos deles não se interessaram. Esses agricultores nativos viviam, sobretudo, da criação de caprinos e ovinos, o chamado "bode solto", também caracterizado como comunidades de fundo de pasto, algo bem típico da região Norte do Estado da Bahia. A pequena produção de culturas de curto ciclo como hortaliças, mandioca, feijão etc. e o trabalho com a pesca, para aqueles que tinham ocupação próxima às margens do rio, também faziam parte das atividades desenvolvidas pelos agricultores familiares da região de Maniçoba.

Após a criação do projeto do perímetro irrigado, foi realizada a divisão dos lotes para a agricultura (lotes menores que variam de 2 a 6 hectares) e lotes para empresas (possuindo até 30 hectares). Após alguns anos, algumas empresas desistiram de produzir naquela localidade, a partir de então foi criada a Associação dos Produtores Rurais de Campos.

A Associação dos Produtores Rurais de Campos possui 72 membros e conta com uma área de 500 hectares. A experiência associativista de Campos foi concebida para beneficiar agricultores familiares e estimular a produção agrícola, através da concepção dos perímetros irrigados no Vale do São Francisco. Os associados pagam o Imposto Territorial pelos lotes que possuem, mas não a escritura, pois as terras são em nome da Associação. Sendo assim eles têm o direito à posse e usufruto dos lotes, no entanto eles não podem ser desvinculados da Associação.

Segundo um levantamento feito pelos próprios entrevistados e pela Associação, atualmente cerca de $90 \%$ dos associados são produtores de manga, sendo os restantes dedicados ao cultivo do coco e de outras culturas com ciclo de produção mais curto, tais como hortaliças e outras frutas. O distrito de Campos fornece a água consumida na produção dos lotes dos agricultores da Associação, sendo que o consumo é individualizado. Já a energia consumida é em nome da 
Associação e rateada por seus membros, apesar de alguns já terem conseguindo fazer a separação do consumo.

\subsection{TRAJETÓRIAS SOCIAIS DOS AGRICULTORES COM A PRODUÇÃO DE MANGA: DOIS CASOS, DUAS EXPERIÊNCIAS DIFERENTES E REVELADORAS}

\subsubsection{O agricultor do caso 1 e seu capital econômico e cultural como ele- mentos estruturadores para sua unidade produtiva}

A primeira experiência de agronegócio familiar que apresentamos com a produção de manga foi identificada e apontada entre os associados como aquela que possui na Associação de Campos o maior número de lotes. O agricultor do caso 1 é natural do município de Nova Canaã (BA), tem 58 anos, e veio de Itajuípe, cidade do Norte de Minas, para Juazeiro há 16 anos, através do convite de seu cunhado. Segundo suas próprias palavras: "sempre fui ligado a terra, meus pais eram agricultores e também 'mexiam' com gado". As disposições para agir do nosso primeiro entrevistado são caracterizadas por um habitus que tem na família sua maior influência para escolha que o levou a continuar com a atividade agropecuária.

Seguindo as tradições de seu grupo familiar, ele trabalhou com cultivo de cacau e também com a criação de bovinos. O agricultor do caso 1 possui um considerado capital cultural, sempre estudou, fez faculdade de licenciatura em agropecuária na Universidade Estadual da Bahia (UNEB), é pai de duas filhas, uma já formada em Engenharia de Produção e a outra está concluindo uma faculdade, ainda em 2016, porém nenhuma delas o auxilia na produção. Questionado sobre o futuro do trabalho com agricultura em seus lotes, o produtor entrevistado revelouse pessimista com a continuidade de sua unidade produtiva, pois sabe que ninguém na família deseja persistir com a agricultura.

Ao chegar a Juazeiro, ele comprou um lote de terras da Associação de Produtores Rurais de Campos, a qual possui autorização de posse e usufruto dos lotes destinados pela CODEVASF nessa área da comunidade rural de Campos. Assim como todos os demais agricultores da Associação, ele revelou que começou sua produção com culturas de ciclo curto, tais como maracujá e pinha. No início da 
experiência nos lotes adquiridos, ele confessou que perdeu $60 \%$ da produção de pinha, após uma forte chuva. Mesmo diante de muitas dificuldades ele conta que continuou a cultivar outras culturas rápidas como tomate e melancia, mas que também obteve prejuízo. Foi somente depois que começou com o cultivo da manga que conseguiu adquirir estabilidade, fato este que ocorre há 14 anos, produzindo, principalmente, a espécie de manga Tommy.

Atualmente possui três lotes na Associação, o que equivale a 7,8 hectares de terra, e também administra outros cinco lotes do seu irmão. Adquiriu recentemente, no ano de 2015, uma propriedade no salitre onde produz banana em uma área de seis hectares e teve sua primeira safra em julho de 2016. Para administrar todos os lotes, o agricultor do caso 1 conta hoje com cinco funcionários permanentes com idade entre 30 e 50 anos.

Em relação à assistência técnica para os lotes que administra, ele contrata a consultoria de um agrônomo, que faz visitas a cada 15 dias. Anteriormente possuía assistência técnica da Plena e Projetec, empresas contratadas pela CODEVASF, através dos recursos arrecadados pela entidade que faz a gestão do perímetro irrigado de Maniçoba, que funciona como uma espécie de associação/conselho de administração. Segundo os depoimentos dos entrevistados já tem mais de um ano que eles não recebem visitas da assistência técnica contratada pelo perímetro irrigado.

Apesar do agricultor do caso 1 fazer a gestão da maior quantidade de lotes entre os produtores da associação, ele afirma que possui dificuldades em obter financiamento bancário para custear as despesas de sua unidade produtiva tais como mão de obra, trator, pulverizador, etc. O último empréstimo realizado foi adquirido no ano de 2014 com vencimento em 2015 através do Programa Nacional de Fortalecimento da Agricultura Familiar (PRONAF). Sua produção, assim como a de outros produtores, só é possível graças à irrigação. $\mathrm{O}$ agricultor pesquisado não é filiado a nenhum sindicado de trabalhador rural, além de não se enquadrar em normas exigidas para o acesso ao PRONAF, no entanto argumenta que, mesmo assim, através de "seus contatos" consegue acessar essa linha de crédito específica.

$\mathrm{Na}$ unidade produtiva do agricultor do caso 1, o método de irrigação utilizado é o de inundação, onde são cavados pequenos sulcos no decorrer das fileiras de plantas fazendo com que a água flua sobre eles. Este método é considerado 
pelos especialistas como muito arcaico, onde o desperdício de água é considerado significativo. Mesmo diante de grave crise hídrica que já persiste há anos no Vale do São Francisco, faltam aos agricultores recursos e consciência sobre a importância do uso racional das águas do rio que oferece nome ao Vale.

$\mathrm{O}$ custo com a água tem uma despesa de quatrocentos a quinhentos reais todos os meses na unidade produtiva do entrevistado, já com a energia elétrica foi graças à "tarifa verde" " que ele obteve uma redução do valor de sua conta, que passou de mil e cem, para cento e oitenta reais mensais. Ele afirma que sua produção varia próximo a algo de 25 a 30 toneladas de manga por hectare, chegando a 32 toneladas no ápice de uma boa colheita. Segundo o agricultor, com a produção de mangas em seus lotes, ele tem uma receita líquida de $\mathrm{R} \$ 35.000,00$ ao ano.

Outro fator relevante na produção é quanto aos gastos com agrotóxicos e adubação, que representa uma fatia de cerca de $70 \%$ dos custos na unidade produtiva. Mas ele argumenta que atualmente vem reduzindo o uso de agrotóxico industrial, e para isso vem fazendo uso de óleo de laranja (Orobó), que tem apresentado eficiência, além de não ser prejudicial ao meio ambiente. O produtor conta atualmente que $90 \%$ da sua produção são comprados pela empresa Bananas EP, sediada no Estado do Espírito Santo, que colhe a sua manga ainda no pé e segundo ele tem "comprado por um preço justo". Os outros $10 \%$ de sua produção são colhidos por trabalhadores avulsos da própria região, contratados por ele e são destinados para o mercado produtor de Juazeiro e ainda o refugo final destinado à produção de polpas de grupos empresariais da própria região.

O agricultor do caso 1 afirma que já negociou, anteriormente, com corretores, que funcionam como atravessadores. Os corretores são agentes bastante conhecidos nos perímetros irrigados do Vale do São Francisco, eles compram dos pequenos produtores e vendem para as grandes empresas, ganhando assim percentual pela negociação, prática essa que deixa o pequeno produtor em dificuldade para propor um preço justo na comercialização de seus produtos. O entrevistado afirmou que sempre procura participar das atividades do Instituto da Fruta, apoiado pelo Sebrae, e sempre que tem oportunidade, também assiste palestras voltadas para a agricultura e a produção de manga.

Ao dizer de sua formação religiosa, o agricultor do caso 1 acredita que

\footnotetext{
$4 \quad$ A Tarifa Verde é uma política criada para atender aos produtores rurais da Companhia de Eletricidade do Estado da Bahia, que oferece redução dos gastos com o consumo de energia à noite.
} 
o seguimento dos preceitos evangélicos e o respeito e senso de justiça para com todos os funcionários, produtores vizinhos, etc., são os pilares para o seu sucesso na produção de manga. Aliado a uma suposta formação moral ele também destaca 0 fato de ter estudado como algo importante para o desenvolvimento do seu trabalho na agricultura.

Nesse caso, destaca-se a importância do capital econômico e cultural para o êxito do produtor. Fatos que podem ser embasados na sua formação acadêmica, nas disposições para agir adquiridas através da influência da família para a atividade agrícola, e por apresentar uma condição de subsistência que lhe proporcionou ferramentas capazes de lhe auxiliar na produção, haja vista também do pouco incentivo governamental que o produtor afirma.

\subsubsection{0 agricultor do caso 2 e o papel do capital social adquirido em sua trajetória social}

Natural de Juazeiro (BA), o agricultor do caso 2 tem 61 anos, há 40 anos mora na comunidade de Mulungú, que conta com cerca de trinta famílias moradoras do lugar, o Mulungú, assim como Campos, pertence ao distrito de Maniçoba. O nosso entrevistado também é membro do Sindicato dos Trabalhadores Rurais do município de Juazeiro, onde é filiado há 30 anos. Católico praticante, ele acha que a igreja foi muito importante para a sua formação, e relata que através dos encontros de formação promovidos pela Diocese de Juazeiro conseguiu adquirir um "um olhar social e crítico sobre o mundo". Também foi filiado ao Partido dos Trabalhadores (PT), do qual se diz não mais militante, enfatizou o entrevistado: "Fico triste com a política, mas acredito que tudo depende dela", afirma o agricultor.

Apesar da pouca formação, o agricultor foi fundador da Associação Comunitária dos Moradores do Mulungú onde foi presidente por várias vezes. Além disso, foi um dos pioneiros na Associação dos Produtores Rurais de Campos exercendo mandato como presidente no período de 2002 a 2006. Ele afirma acreditar que "por não ter estudado só conseguiu adquirir conhecimento correndo atrás das técnicas, indo a reuniões e procurando sempre inovações para a produção", e conclui: "Penso que minha experiência como presidente me ajudou a ter contatos, 
conheço todo mundo".

Nosso segundo entrevistado se comunica com facilidade e demonstra grande capacidade de articulação social, ou seja, possui inúmeros contatos, amigos e conhecimento sobre as redes de relacionamento político na agricultura familiar. As experiências do nosso entrevistado na presidência de associações são resultados de anos de engajamento e formação, não na escola formal, e sim nos espaços de sociabilidade como igreja, sindicato, partido político etc.

Sempre foi agricultor e, antes de produzir manga, trabalhava com culturas de curto ciclo como feijão, mandioca, maracujá, melancia e milho, toda a produção era destinada para o autoconsumo da sua família, a chamada agricultura de subsistência. Ele conta que há 19 anos adquiriu seu lote na Associação de Produtores Rurais de Campos, o que equivale a uma área de terra de 6 hectares.

Sobre a mudança na prática de culturas de ciclos curtos para as de ciclo mais longo, o produtor afirmou que a orientação de pesquisadores da CODEVASF para o cultivo de gêneros agrícolas com valor agregado maior, dentre elas a manga, foi de extrema importância para os pequenos agricultores. O distrito de Maniçoba, através dos recursos arrecadados, fornece assistência técnica através de cursos e palestras ministradas, entre outros, pelo agrônomo Eduardo Ferraz, e que ele enquanto produtor faz questão de sempre participar.

Os agricultores pesquisados têm a compreensão de que a adoção da manga no cultivo para os lotes de terras da Associação de Campos conseguiu melhorar a qualidade de vida de seus integrantes, que deixaram a agricultura de subsistência e passaram a obter uma melhoria em seus ganhos econômicos com agricultura. Além disso, após a adoção da manga, os produtores da associação obtiveram uma redução de $80 \%$ no uso de agrotóxicos, algo que não era possível com a produção das culturas de ciclo curto, que exigiam o uso mais intensivo de fertilizantes, adubos químicos e pesticidas.

O agricultor do caso 2 afirma que sua produção é de 30 toneladas de manga por hectare, e assim como muitos outros agricultores da Associação, também irriga por inundação, suas despesas com água são de seiscentos reais mensais e de trezentos reais com energia elétrica. Atualmente, produz manga Tommy e manga Palmer, que para ele possuem uma lucratividade maior junto ao mercado. Assim como é para 
outros agricultores familiares, o agricultor do caso 2 tem sua produção negociada por um corretor, que se responsabiliza pela colheita e transporte da manga até o comprador final.

Os associados de Campos já tentaram criar uma cooperativa para facilitar a comercialização da produção agrícola de seus produtores, porém a experiência não foi exitosa. A ideia de uma cooperativa seria uma estratégia dos produtores rurais da Associação de Campos de não mais dependerem da intermediação do agente corretor na comercialização da manga. Os produtores sabem que se não dependessem do corretor para efetuarem suas vendas eles teriam uma margem maior de lucros. $\mathrm{O}$ corretor persiste nas relações mercantis no perímetro irrigado de Maniçoba e em todo Vale do São Francisco, por um lado devido à falta de capital econômico para que os pequenos agricultores construam uma logística capaz de facilitar a venda e compra de seus produtos, e por outro lado a maioria dos agricultores por falta de habilidade e/ou conhecimento contábil apresenta dificuldade em se relacionar com empresas privadas e demais compradores.

Sobre sua família, o agricultor do caso 2 conta com a ajuda de todos os integrantes para o trabalho em sua unidade produtiva: a esposa, três filhos e um genro, que contribuem com as atividades necessárias para sua manutenção. Um de seus filhos estudou até a $8^{\mathrm{a}}$ série e os outros dois até o $2^{\circ}$ ano do ensino médio, ou seja, nenhum de seus filhos conseguiu concluir o ensino médio. A baixa escolaridade dessa família é emblemática do que ainda ocorre em muitas áreas rurais e pode se reverter em certos casos em dificuldades para os agricultores expandirem sua produção e conquistar mercados.

Ele argumenta que sempre incentivou para que seus filhos prosseguissem com os estudos, mas que assim como tantos outros moradores da comunidade onde vivem, acabaram preferindo a dedicação apenas à agricultura. Ele também lembra que não teve oportunidade de estudar, pois na sua época não existiam escolas próximas, além de pertencer a uma família muito pobre e não tinha condições de morar na sede do município para se dedicar aos estudos, mas lamenta muito não ter tido essa oportunidade. Os filhos do nosso segundo caso estudado gostam do trabalho na agricultura e pretendem continuar o trabalho do pai.

\section{CONSIDERAÇÕES FINAIS}


As análises das trajetórias dos agricultores pesquisados apontam para duas diferentes maneiras de como esses agricultores no distrito do perímetro irrigado de Maniçoba têm se apropriado de recursos e se posicionado socialmente no campo de relações dos produtores de Manga no Vale do São Francisco. A pesquisa realizada fez um recorte no estudo das práticas econômicas identificadas no agronegócio, a partir de duas experiências com a pequena produção, aqui chamadas de "agronegócio familiar".

Identificou-se no artigo um compartilhamento de uma mesma inciativa de agricultores no cultivo irrigado voltado para pequena e média produção, através do projeto idealizado pela CODEVASF para agricultores familiares da Associação de Produtores Rurais de Campos. Nossos entrevistados, aqui identificados como agricultor do caso 1 e agricultor do caso 2, apresentaram similaridades em trajetórias, que se limitam apenas a dois aspectos: filiação à experiência associativa de Campos; e ao seus interesses comuns pelo cultivo e comercialização da manga.

Enquanto o caso do agricultor 1 revela um babitus forjado ao longo de uma trajetória marcada por acúmulos diferentes de capital tais como o econômico e cultural, o caso do agricultor 2 mostra uma trajetória diferente onde o capital social foi a forma mais determinante de como esse produtor rural conseguiu sua posição no campo de relações no qual ele atua. As trajetórias dos agricultores pesquisados no trabalho de campo realizado são reveladoras de oportunidades conquistadas com base em recursos muito específicos.

$\mathrm{O}$ caso do agricultor 1 é marcado pelo acúmulo de bens materiais que fizeram com que sua família lhe proporcionasse estudar e cursar uma faculdade na área de ciências agrárias, e isso se repetiu na segunda geração de sua família, onde ele também fez o mesmo com suas filhas. Nesse caso observa-se um babitus internalizado, com esquemas mentais formadores de uma prática construída com base no acesso ao capital econômico e cultural que tem origem em sua família. Bourdieu (2011b) também reflete que a tendência de todo campo relacional é reproduzir, conservar as posições de seus integrantes, ou seja, se o agricultor do caso 1 conseguiu estudar e conquistar uma série de privilégios de classe dentro dos seus ciclos de relações, a tendência é que os seus filhos sigam o mesmo caminho, 
nesse caso, foi o estudo e a posição de poder cursar uma faculdade.

Também é importante destacar como o acúmulo de uma forma de capital pode levar a aquisição de outro tipo de capital: capital econômico/capital cultural e vice versa. Mas é importante problematizar - e o que isso tem a ver com o fato deles produzirem manga? O que é relevante para esse trabalho? A princípio está tudo relacionado, pois compreender a trajetória social desses agricultores revela suas dificuldades e facilidades na prática do agronegócio. A ideia aqui é desconstruir o princípio propagado de que uns têm vocação e outros não! É ressignificar concepções estereotipadas e estigmatizadoras do "acomodado", "preguiçoso" e do desinteressado.

Nesse estudo, os agentes sociais, agricultores, têm nas suas formas de agir e entender o mundo elementos que podem subjugá-los a uma realidade de muita desigualdade e conservar posições de poder presentes naquele determinado grupo social, campo relacional, que é a Associação de Produtores Rurais de Campos. O agricultor do caso 1 é um privilegiado dentro de sua associação, ele é o maior detentor de lotes entre os associados; ele é aquele que não precisa do agente corretor para intermediar o seu comércio de manga, e o resultado dessa situação de poder é a obtenção de melhores lucros. O agricultor do caso 1 é reconhecidamente o grande produtor da Associação, quando se considera uma comparação com os demais sócios. Ele é visto como aquele que "deu certo", que os demais devem e precisam copiar. Nessa perspectiva, o agricultor do caso 1 conquistou o que Bourdieu (2011b) chama de capital simbólico: honra, status - reconhecimento de poder entre seus pares do mesmo campo relacional.

Já o agricultor do caso 2 não possui capital cultural (escolaridade, títulos) e nunca teve capital econômico como algo que fosse determinante para a sua prática e continuidade enquanto agricultor. $\mathrm{O}$ agricultor do caso 2, para não ter que reproduzir as mesmas situações de muitos outros agricultores que receberam lotes de terras, através da Associação de Produtores de Campos, ou seja, situação de dificuldade e mesmo de ter que se desfazer de seu lote, vendendo para outro agricultor, ele recorreu a uma outra forma de capital: o social.

O agricultor do caso 2 teve seu habitus fortemente influenciado por uma trajetória social onde teve a oportunidade de construir uma rede de relacionamentos, que o proporcionou, como o próprio afirmou - "ser desenrolado". Foi a partir de suas 
experiências de participação contínua que o agricultor do caso 2 resistiu na prática da comercialização da manga em seu lote na Associação de Campos. Esse recurso relacional, capital social, é fundamental para que esse agricultor, ao contrário de muitos outros, continue no agronegócio familiar da manga.

A capacidade dos agentes sociais, agricultores, reagirem aos supostos condicionamentos sociais é identificada no estudo do caso do agricultor 2. Ele tinha tudo para não mais produzir em seu lote na Associação, assim como muitos agricultores que também adquiriram lotes na Associação, uma vez que a rotatividade de agricultores nos lotes da associação é grande.

Para o agricultor do caso 1 é fácil dizer que "a terra deve ser dada para quem de fato deseja trabalhar", essa é uma expressão bem clichê, mas bastante usada. Nosso papel na academia na área dos estudos rurais é problematizar a realidade e não reproduzir discursos políticos que quase sempre atendem a demandas de um grupo social alojado em posições de poder em um determinado campo de relações, nesse caso falamos do agronegócio e suas interfaces com outros campos relacionais, a exemplo do que acontece na política institucional e no jurídico.

\section{REFERÊNCIAS}

BAQUERO, M. Raízes do Capital Social. In: BAQUERO, M. (Org.). Reiventando a sociedade na América Latina: cultura política, gênero, exclusão e capital social. Porto Alegre: Universitária, 2001.

BOURDIEU, Pierre. O Poder Simbólico. 15. ed. Rio de Janeiro: Bertrand Brasil, 2011a.

BOURDIEU, Pierre. Coisas Ditas. São Paulo: Brasiliense, 2011b.

COMPANHIA DE DESENVOLVIMENTO DOS VALES DO SÃO FRANCISCO E DO PARNAÍBA - CODEVASF. Disponível em: < http://www.codevasf.gov.br/principal/ perimetros-irrigados/elenco-de-projetos/manicoba > . Acesso em: 10 ago. 2016.

DISTRITO DE IRRIGAÇÃO DO PERÍMETRO DE MANIÇOBA - DIM. Disponível em: < http://www.dim.org.br/index2.php?pg = oprojeto > . Acesso em: 10 ago. 2016. 
DELGADO, G. A questão agrária no Brasil, 1950-2003. In: JACCOUD, L. (Ed.). Questão social e políticas sociais no Brasil contemporâneo. Brasília: IPEA, 2005, p. 51-90. Disponível em: < http://www.ipea.gov.br/portal/images/stories/PDFs/livros/ Cap_2-10.pdf $>$. Acesso em: 10 ago. 2016.

FAVARETO, A. S. Um balanço das políticas de desenvolvimento territorial rural no Brasil: uma década de experimentações. São Paulo: Desenvolvimento em Debate (INCT/PPED), 210. v. 1, p. 47-63. Disponível em: <http://www.rimisp.org/wpcontent/uploads/2013/03/15.pdf> . Acesso em: 05 ago. 2016.

SILVA, J. G.; DEL GROSSI, M. E. O novo rural brasileiro. Oficina Temática do Projeto RURBANO. Disponível em: <http://www.iapar.br/arquivos/File/zip_pdf/novo_ rural_br.pdf $>$. Acesso em: 09 ago. 2016.

HEREDIA, B.; PALMEIRA, M.; LEITE, S. P. Sociedade e Economia do "Agronegócio" no Brasil. Revista Brasileira de Ciências Sociais, v. 25, n. 74, 2010. Disponível em: $<$ http://www.scielo.br/pdf/rbcsoc/v25n74/a10v2574.pdf>. Acesso em: 05 ago. 2016.

NEVES, D. P. A agricultura familiar e o coadjuvante quadro institucional. In: ENSAIOS: Desenvolvimento rural e transformações na agricultura. EMBRAPA, UFS, 2002 p. 3152. Disponível em: <http://ivimagens.sct.embrapa.br/amostras/00071350.pdf>. Acesso em: 07 ago. 2016.

PUTNAM, R. D. Comunidade e democracia: a experiência da Itália moderna. Rio de Janeiro: Fundação Getúlio Vargas, 1996.

Recebido em: 27 setembro de 2016 Aceito em: 01 de março de 2017 